\title{
As consequencias da censura na dramaturgia de Plínio Marcos
}

The consequences of the censorship in the dramaturgy of Plínio Marcos

Fernando Freitas dos Santos ${ }^{1}$ 


\section{Resumo}

O presente artigo visa analisar a participação do dramaturgo Plínio Marcos na turbulenta vida cultural brasileira no período ditatorial. Plínio Marcos é um dos autores teatrais mais importantes do teatro brasileiro na época da ditadura militar. Nascido em Santos, em 1935, escreveu peças de grande sensibilidade, levando para o palco a realidade das classes sociais do subproletariado urbano. Suas peças abrem caminho para os protestos de grupos que se julgam oprimidos: biscateiros, prostitutas, travestis, mendigos, cafetões, catadores de papel. Os dramas de Plínio Marcos atribuem ao social um pano de fundo que salienta os conflitos interindividuais, forçosamente psicológicos. Movido por um forte sentido de solidariedade humana e com as armas de um talento que alguns julgam questionável, Plínio faz de suas peças um libelo à dura realidade dos marginalizados e lança à sociedade e à cultura um desafio a certa obrigação ética de tratar a realidade cruamente. Isto implica a reavaliação de toda a estrutura social e um certo compromisso de transformação, que Plínio Marcos alcança através da identidade marginal de seus personagens e a sua auto-caracterização como autor marginal.

Palavras-Chave: Plínio Marcos, censura, marginalidade, ditadura militar.

\section{Abstract}

This article aims to analyze the participation of playwright Plínio Marcos the turbulent Brazilian cultural life in the dictatorship period. Plinio Marcos is an of the most important playwrights of the Brazilian theater during the military dictatorship. Born in Santos, in 1935, wrote pieces of great sensitivity, taking the stage to the reality of social classes of the urban sub-proletariat. His pieces give way to protests from groups that consider themselves oppressed: prostitutes, transvestites, beggars, pimps, paper collectors. The dramas of social Plinio Marcos attach to a backdrop that emphasizes the necessarily interpersonal psychological conflicts. Driven by a strong sense of human solidarity and with the arms of a talent that some deem questionable, Plínio Marcos his pieces a libel to the harsh reality of the marginalized and launches the society and culture a challenge to certain ethical obligation to treat the reality crudely. This implies a reassessment of the entire social structure and a certain commitment to transformation, which Plinio Marcos reaches through the marginal of his characters and his self-characterization as marginal author identity.

Keywords: Plinio Marcos, censorship, marginalization, military dictatorship. 


\section{A produção cultural no período ditatorial}

Em 31 de março de 1964 militares assumem o governo brasileiro por meio de um golpe, e permanecem a governar o país durante vinte e um anos, instalando um regime ditatorial. Esse período é marcado pela censura e pelas perseguições políticas de toda ordem. Os trabalhos teatrais que buscavam questionar a realidade brasileira sofriam repressões por meio de peças proibidas, canceladas e cortadas, que acabavam por perder sua verdadeira essência.

Tal situação fez com que grandes nomes e grupos de teatro estivessem no foco da censura, por apresentarem posturas consideradas hostis ao governo em face da liberdade de expressão sobre situações sociais injustas. Deste rol fazem parte Augusto Boal, criador do Teatro do Oprimido e integrante do grupo de teatro Arena, perseguido, ficou exilado durante todo o regime; José Celso Martinez Corrêa, diretor, dramaturgo e encenador, integrante do teatro oficina, exilado de 1974 a 1978; Ferreira Gullar, Tereza Aragão e Armando Costa, sócios fundadores do grupo Opinião que encenou a peça Liberdade, Liberdade, dirigida por Flávio Rangel e texto de Millôr Fernandes; e Plínio Marcos, autor censurado pela ousadia de levar aos palcos e dar voz à personagens marginalizados. Por este aspecto, a presente pesquisa objetiva registrar a participação deste dramaturgo na turbulenta vida cultural brasileira no período da ditadura militar.

Grupos teatrais, como o Oficina, Arena e o Opinião, que realizavam importantes trabalhos no teatro brasileiro, foram dizimados a partir da publicação do Ato Institucional № 5 (Al-5), documento este, que restringia os direitos dos cidadãos ao estabelecer a confirmação de plenos poderes do governo. Mesmo que não tivesse conteúdo diretamente político, a repressão perseguia qualquer peça ou movimento que não fosse do interesse dos militares. O Al-5 foi considerado "antilei e antidireito", uma vez que não respeita os preceitos básicos constitucionais, instaurando insegurança política e instabilidade (FREIRE, 1977).

O período sob a tutela do regime militar foi muito atribulado para a dramaturgia brasileira, visto que companhias de teatro refugiavam-se em espaços alternativos, pois para o governo militar a arte era um perigoso instrumento de agitação política a fim de denunciar a situação vigente do país. Assim sendo, todos os textos teatrais passavam pelo crivo da censura, obrigando os autores a resolver com as autoridades censoras a liberação dos textos. Tais autoridades viam a classe teatral como intelectuais desvairados e vagabundos.

Olga Reverbel demonstra sua preocupação em relação as companhias teatrais que encenavam textos de protestos:

\footnotetext{
Os homens do teatro de Arena, Oficina e Opinião, atentos a luta política travada dentro e fora do palco, mantiveram-se voltados para a pesquisa e experiência estética teatral. O golpe militar surpreendeu o Arena encenando Tartufo, de Moliére que, sem sofrer alteração, era muito bem recebido por uma platéia capaz de perceber a critica à situação em que se vivia. Boal dirigia o Opinião no Rio, enquanto o grupo paulista, tendo à frente Guarnieri, cria Arena conta Zumbi, um espetáculo estruturado sobre uma base dramática mais densa, transformando em personagens os negros dos quilombos (REVERBEL, 1987, p.112).
} 
Metáforas e alegorias eram as alternativas utilizadas pelos artistas para evitar o crivo da censura. O foco central incidia na crítica ao regime militar, exaltando principalmente a liberdade de expressão. Chico Buarque de Holanda, artista brasileiro, conhecido pelas fortes letras de protesto de suas composições musicais, assinala a dificuldade de se expressar no período ditatorial e ainda ressalta que tal questão acaba por "datar" o trabalho artístico:

O artista, com o trabalho da censura, corre o risco de ter um álibi até para se esforçar menos. Ou o artista é até obrigado a fazer ginásticas incríveis, usar de metáforas às vezes que, com o passar do tempo, parecem ridículas. [...] Depois passa o tempo e o texto fica vazio, a forma mesma é alterada na medida em que você procura mil artimanhas para tentar passar uma idéia (HOLLANDA apud HÉDE, 1981, p. 178).

O dramaturgo afirma, talvez em excesso, que a dramaturgia brasileira antes de 1968 era considerada uma potência para os demais países. No entanto, em 1968, o regime foi incisivo e agravou a situação dos dramaturgos. Peças que retratavam a realidade nacional da época foram impedidas de serem levadas aos palcos. Para Plínio Marcos, foi extirpada a tessitura vívida do teatro que apenas sobrevivia langorosamente em meio ao caos ditatorial. "A partir de 68, veio o rapa, e a barba cresceu. Cresceu e teatro então teve que partir para a sobrevivência apenas" (MARCOS, 1976, p. 50).

Conforme o regime se consolidava, protestos sociais ganhavam destaque no cenário nacional sob comando de artistas e intelectuais que se negavam a seguir o que era exigido pelos governantes, afirmando que o fundamento primordial da arte incidia no exercício da liberdade. Dias Gomes, autor de importantes peças teatrais como O Santo Inquérito, O Pagador de Promessas e A Invasão, também passou pelo crivo da censura, sofrendo proibição do texto $O$ Berço do Herói. O dramaturgo aponta que a luta pela liberdade não era somente da classe artística, mas do povo brasileiro. O autor assevera, que a liberdade de expressão era um desejo de todos aqueles que estavam sob os poderes de um arbitrário cultural, e por tal motivo considera os protestos em prol da liberdade de expressão como uma "luta é una e indivisível". (GOMES, 1968).

\section{Plínio Marcos em Cena: breve biografia' ${ }^{1}$}

Plínio Marcos nasceu na cidade de Santos (SP) no dia 29 de setembro de 1935 e morreu no dia 19 de novembro de 1999, depois de uma internação de 27 dias no Instituto do Coração, em São Paulo. Filho de bancário e dona de casa, seu primeiro emprego foi como funileiro, profissão esta que consta em sua carteira de

reservita. Influenciado por seu pai, começou a vender livros espíritas na Praça de Santos, porém sonhava ser jogador profissional de futebol, aspiração esta que o influenciou para escrever crônicas de matérias esportistas.

\footnotetext{
As informação biográficas de Plinio Marcos abordadas neste artigo estão disponíveis em: www.pliniomarcos.com, site oficial de Plínio Marcos, criado e organizado por seus filhos. Acesso em: 25 abril 2013.
} 
Motivado em conquistar uma garota que morava no circo que passava por Santos, Plínio iniciou sua carreira artística. O palhaço Frajola foi o personagem de maior destaque. A partir deste, foi solicitado por Patrícia Galvão à substituir um ator na montagem da peça infantil Pluft, o fantasminha de Maria Clara Machado. Plínio integrou o grupo de teatro amador santista e deu início a sua carreira de ator.

Em 1968 começou a trabalhar como jornalista no jornal Última Hora. Escrevia crônicas sobre cinema, esportes e problemas sociais. Em relação as matérias esportivas se dedicava majoritariamente ao futebol, sua paixão de infância. Nas crônicas de cunho social, Plínio evidenciava a classe subalterna e marginalizada. Tais apontamentos, fez com que as crônicas de Plínio sofressem cortes, acarretando sua demissão do jornal a mando do regime militar:

Em meados dos anos setenta, certa noite, na TV TUPI, ao invés de lançar o programa político no ar, trocou-o por uma série de desenhos animados. A ousadia custou-lhe o emprego, coisa que lhe importava menos do que a liberdade de expressão. Nas décadas de sessenta e setenta perdeu o emprego inúmeras vezes, não raro sem explicação convincente, ao menos para ele. (CONTIERO, 2007, p.213).

Plínio Marcos concluiu apenas o ensino primário, sendo este um dos motivos de suas peças não apresentarem uma linguagem rebuscada, pelo contrário, eram dotadas de palavrões: "Quando comecei a escrever, tinha vinte palavras no meu vocabulário e usava o palavrão que servia de sinônimo para palavras que não conhecia. Foi assim que consegui dar minha participação e fazer reportagens sobre a realidade nacional." (MARCOS apud KHÉDE, 1981, p.197). Plínio orgulha-se por não ter cursado nível superior e atribui sua experiência erudita à influência de importantes. artistas, como Patrícia Galvão e Geraldo Ferraz, autor de Douramundo, com quem pode estabelecer relação de convívio em maior grau:

Recebi toda a influência da cultura erudita [...]. Quando fui impedido de trabalhar em jornal, televisão, em teatro e em todos os lugares, peguei minha mala de livros e fui vender meus livros. Foi assim que cheguei em São Paulo: como camelô. Não abdico nada que é da minha cultura popular. (MARCOS apud KHÉDE, 1981, p. 201)

Um dos motivos para que seus textos marquem a dramaturgia nacional se deve às ações motivadas pelo ódio de suas personagens. Plínio acompanhou de perto dilemas de grupo sociais marginalizados, trata-se, como entende Freire, de um "caso típico de literatura testemunhal" (FREIRE, 1977, p.36). Por esta razão apresenta tanta propriedade ao escrever textos tão verossímeis à realidade marginal.

\section{Características da dramaturgia de Plínio Marcos}

O que promove a marginalidade, explica Germani (1970), é um processo social assincrônico, ou seja, a disparidade dos níveis de integração, desenvolvimento e participação de determinada parcela da sociedade. Essa falta de sincronia aponta para a coexistência cronológica de categorias sociais com diferentes graus de desenvolvimento e diferenças observáveis nas instituições, nos valores e nas atitudes. 
Assim, tendem à marginalização de grupos ou categorias sociais, e até mesmo áreas geográficas, que se encontram em situações de atraso e /ou exclusão. Embora possa haver nessa exclusão muito de responsabilidade pessoal, na dramaturgia de Plínio os miseráveis se apresentam como vitimas dessa assincronia do processo social. Assim sendo, nos textos de Plínio é evidente a presença de personagens em condições de subalternidade, ou seja, à margem da sociedade. A dramaturgia do autor então apresenta como foco a denúncia social, o descaso e a luta pela sobrevivência, de modo a permear a temática da violência.

Em uma crônica ao jornal Última Hora, Plínio escreve sobre a marginalidade no porto de Santos, lugar onde viveu boa parte de sua vida e pôde acompanhar de perto a classe subalterna, motivo pelo qual contribui para a elaboração de sua dramaturgia e consequentemente a justificativa da agressividade de seus personagens:

O cais do Porto de Santos já foi uma das bocas de fogo das mais pesadas do mundo. Lá era broca. Ninguém enjeitava pau. O bicho que fugia do cacete não aparecia mais. Se desse as caras, virava o esparro. A curriola pegava no pé, dava biaba e esculachava. A ordem lá no golfo era encarar. Sempre. Do jeito que desse e viesse. Apanhar não é feio. Pega mau é tirar o time de campo na hora do sarrafo... Então o negócio era na base do agrião. Ninguém deixava nada no barato. E os valentes eram linha de frente mesmo. (MARCOS, 1969).

Marcos Freire considera Plínio Marcos um "símbolo do teatro brasileiro", uma vez que é o dramaturgo com o maior número de peças censuradas do Brasil ao abordar temáticas relacionadas aos problemas sociais. (FREIRE, 1977, p. 37).

Plínio declarou, no "Ciclo de Debates" do Teatro Casa Grande, ocorrido no Rio de Janeiro em 14 de abril de 1975, que:

Quanto ao teatro político, eu particularmente não sou favorável a esse tipo de teatro. Gosto do teatro social, e explico por que: teatro político, teatro que faz pregação de idéias políticas, só atinge a quem concorda, enquanto a colocação do problema social é mais ampla, permite discutir, abrir o diálogo com pessoas que são indiferentes. Esse é o meu ponto de vista. (MARCOS, 1976, p.56).

Considero esta declaração de Plinio Marcos apartidária, no entanto, política. Conforme salienta Aristóteles, o homem como um ser dotado de fala é um ser político. A origem da coletividade é estabelecida por um pacto original, tendo aceitação dos indivíduos, de modo a ter uma referência de poder ou líder político. $O$ político por toda via deve atentar-se à pluralidade social para que seu governo não seja monovalente, direcionado a uma visão linear. A política, portanto, é uma doutrina moral social, de maneira que a coletividade é superior aos interesses individuais, ou seja, o bem comum é superior ao bem particular, e o estado intervém na vida social para assegurar a harmonia e equalizar as necessidades sociais (ARISTÓTELES, 2001). Por tais motivos, a dramaturgia pliniana coloca em evidencia um olhar político ao criticar o poder que atende somente as necessidades individuais e que não se preocupa com os menos favorecidos e marginalizados.

Ademais, para Boal, "todo teatro é necessariamente político, porque políticas são todas as atividades do homem, e o teatro é uma delas" (BOAL, 2008, p.12). Segundo ele, o teatro era uma festa em que toda e qualquer pessoa podia partici- 
par livremente, todos eram criadores e espectadores. Porém, com a intervenção da aristocracia, houve algumas alterações, de modo a impedir que todos participassem, estabelecendo divisões onde apenas algumas pessoas poderiam atuar e as demais seriam apenas platéia. Para que a ideologia dessa classe dominante fosse refletida de forma eficiente para o público, os atores protagonistas só podiam ser aristocratas, enquanto os demais seriam o coro, de modo a representar a massa. Desse modo, Plínio Marcos ao levar à cena personagens do submundo, como prostitutas, travestis, mendigos, cafetões e catadores de papel, faz com que todos sejam protagonistas e coro. Seu teatro é político social e não partidário. Ele critica o teatro envolvido com uma ideologia direta, mas sua ação é política.

Uma das características que constituem a identidade pliniana é a aliança do grotesco com o calão. Para um melhor entendimento do grotesco, o teórico russo Bakhtin pontua que: "O traço marcante do realismo grotesco é o rebaixamento, isto é a transferência ao plano material e corporal, o da terra e do corpo na sua indissolúvel unidade, de que tudo é elevado, espiritual, ideal e abstrato" (BAKHTIN, 1993ā , p.18). Nota-se então uma antinomia, ou seja, uma tendência paradoxal do alto relacionado ao sublime e do baixo identificado como grotesco, a fim de enfatizar a noção de negatividade. A etimologia do termo monstrum provém do latim e tem o sentido de estranho e extraordinário:

[...] as imagens grotescas conservam uma natureza original, diferenciam-se claramente das imagens da vida cotidiana, preestabelecidas e perfeitas. São imagens ambivalentes e contraditórias que parecem disformes, monstruosas e horrendas, se consideradas do ponto de vista da estética "clássica", isto é, da estética da vida cotidiana preestabelecida e completa. (BAKHTIN, 2008, p.22).

O grotesco na dramaturgia pliniana é demonstrado a partir da potencial provocação de sentimentos de horror do espectador, ao assistir cenas como o aborto da personagem Nina do texto Quando as Máquinas Param (1967). O texto narra a história de um jovem casal, Nina e Zé, que passa por uma crise financeira, e se agrava com a gravidez de Nina. Seu esposo pede para que o filho seja abortado, pedido este recusado pela cônjuge:

Eu não sei mais nada, Zé. Sempre estive do seu lado. Topei todas as paradas com você. Desde que casamos, nunca fomos num cinema, nunca passeamos, nunca comprei um vestido novo e nunca me queixei. [...] E assim, a gente ia. Aos trancos e barrancos, mas ia! Íamos ter filhos, íamos ser como todo mundo. [...] Agora, não sei. Não sei mais nada. Só sei que estou grávida. E vou ter meu filho. (MARCOS, 1962, p.60).

A personagem Nina ameaça abandonar o marido e ir morar com sua mãe, caso continue com o intuito de abortar seu filho. Zé, em um ato de desespero e desequilíbrio, desfere um soco na barriga da mulher e interrompe sua gravidez.

Mario Cacciaglia atribui à dramaturgia de Plínio Marcos uma "violência extrema" em que o "homem é retratado numa situação limite na qual regride ao animalesco", caracterizando a presença do grotesco e/ou horror estético pliniano (CACCIAGLIA, 1986, p.134). O grotesco evidencia a quebra dos padrões, como uma espécie de desordem. Tal situação designa a monstruosidade do marido de não controlar seu 
ato e desferir um soco na esposa ocasionando o aborto de seu filho. A cena tem a potência de provocar no público um sentimento de horror, uma vez que utilizar de meios violentos para que a gravidez da mãe de seu filho seja interrompida, não é uma atitude da "natureza original" de um pai considerada compreensível.

O uso do baixo calão é corriqueiro nos textos de Plínio Marcos. Ressalta-se que as palavras consideradas por muitos despudoradas, são dotadas de intencionalidade. A peça Navalha na Carne, escrita no final da década de 1960, carregada dessa linguagem despudorada, apresenta alto teor de violência. A trama se passa num quarto de pensão que é divido por Neusa Sueli, prostituta decadente; Vado, cafetão viciado em drogas; e Veludo, camareiro homossexual. O conflito inicia-se com Vado utilizando meios agressivos com a prostituta Neusa Sueli, por não ter repassado o dinheiro que o mesmo viera buscar, e que, antes de sair da pensão, havia deixado sobre o criado mudo, e que desaparecera. Agressão verbal, como: "puta velha", "porca", "nojenta", "perebenta" aliada à violência física, permeia tal ambiente. Veludo, suspeito de roubar o dinheiro, sob ameaça de Neusa Sueli que encosta uma navalha em seu rosto, confessa o furto.

A peça, ao passar pela censura, foi proibida. Conforme salienta Plínio, os censores definiram Navalha na Carne como um "amontoado de palavrões". Para driblar tal afirmação, o argumento utilizado pelo dramaturgo é que, ao ser levada ao palco, o uso de palavrões, aliado à "sensibilidade da atriz, ganha uma dimensão de poesia" (MARCOS apud KHÉDE, 1981, p.191). O crítico Yan Michalski salienta que a peça apresenta "extrema densidade do clima", e a reação do expectador ao presenciar tanta violência se dá por meio da "respiração presa, e a cujo fascínio não escapa nem o público mais conservador" (MICHALSKI, 2005, p.97).

O palavrão, nas peças de Plínio, não se dá de forma gratuita, pelo contrário, apresenta o intuito de demonstrar ironia e revolta social; o uso de tal linguagem é considerado pelo dramaturgo como mecanismo eficaz de se aproximar da classe subalterna e marginalizada e retratar a realidade tal como ela é:

\footnotetext{
Lamentavelmente, em nosso país as pessoas que têm cultura erudita não falam a mesma língua do povo. Por isso é que se chocam com os palavrões. [...] toda vez que retrato as situações sociais dos menos favorecidos, uso o palavrão, porque essa é a linguagem deles. [...] povo tem uma cultura muito rica e que precisa ser preservada. E preservada ao modo do povo, e não impondo-lhes os nossos padrões de cultura, pois assim acabaremos liquidando a cultura popular, como a liquidamos nas escolas de samba que estão aí. (MARCOS apud KHÉDE, 1981, p.198).
}

Além do calão, a constante temática do homossexualismo é revelada na dramaturgia pliniana em textos como Barrela (1958), Dois perdidos numa noite suja (1966), Abajur Lilás (1975), Navalha na Carne (1967) e Mancha Roxa (1988). A maneira como o homossexual é abordado pelos demais personagens nos textos de Plínio Marcos evidencia uma desqualificação, ou seja, o modo desprezível que muitas vezes é visto pela sociedade. Ao levar para o palco tal tema, Plínio convida o expectador a refletir sobre o preconceito que os homossexuais enfrentam. Em Navalha na Carne, o faxineiro homossexual Veludo é vítima de humilhação. 
A nomenclatura "veado", considerada como apelido vexatório, tem a finalidade de demonstrar o preconceito e a repulsa das demais personagens heterossexuais, que por situações.

adversas se veem obrigados a conviver com o homossexual. Tal afirmação é ratificada pelo discurso de Giro, cafetão homossexual, em Abajur Lilás:

GIRO - Ela fica apavorada só de pensar que o filhinho dela pode sair bicha.(Ri nervoso). Tu tem nojo de veado, né? Tu deve ter nojo de mim. Eu sei.

Tu me engole porque depende do meu mocó. Só por isso. Se tu pudesse, tu me expulsava daqui agora mesmo. Eu sei que tu, a Célia, os homens lá debaixo, os que me ajudam a tomar conta das minhas putas, os policiais, todo mundo tem raiva de mim. Todo mundo. $\mathrm{O}$ desgraçado que toma meu dinheiro, o garçom do botequim fedorento que serve aquela comida porca, o cozinheiro, todo mundo. Até os fregueses desse treme-treme têm raiva de mim. Inveja. Tudo inveja. Morrem de inveja de mim. Sou puto, nojento e tudo o mais. Mas não preciso de ninguém. Nem dou bola. Venho aqui como amigo. Estou só querendo levar um papo. Mas não posso. Tu tem inveja. Não se conforma de ter que ganhar o teu pão numa cama que é minha. É como o garçom que se dobra com nojo pra apanhar a gorjeta que eu deixo.

$\mathrm{E}$ os filhos-da-puta todos que vivem às custas das propinas que eu dou. Eu, mais ninguém. Eles têm bronca. Mas eu quero que tu, a Célia, todo mundo vá à merda. $\mathrm{Eu}$ juntei dinheiro. Tenho coisas. E todos aqui neste prédio dependem de mim. Todos. Os que não acreditam, é só se assanharem pra ver. Sou veado, mas não sou bunda-mole. Sei viver. Se alguém quiser engrossar, pago uns homens e mando bater, matar e os cambaus. Tenho dinheiro e posso mais que todos aqui. E tu que abra o olho. Não vou esquecer que tu me chamou de veado nojento. (MARCOS: 2003, p.185).

Terminologias como "veado", "bichona", "boneca", "fresco" nos textos de Plínio, são direcionadas a homens que apresentam gestualidade estereotipada com trejeitos femininos ou também, aqueles que sofreram violência sexual por outro homem. Tais termos, direcionados à personagens heterossexuais, são considerados como afronta a sua masculinidade viril. Em Dois Perdidos Numa Noite Suja, Paco demonstra irritação quando colocam em "xeque" sua sexualidade:

PACO - [...]. Mas se um cara começa a dizer pra todo mundo que eu sou fresco e os cambaus, eu ferro o miserável. Comigo é assim. Pode ser quem for; folgou, dou pau. (Pausa.) Como é? Você vai fazer como eu, ou vai dar pra trás? (MARCOS, 2003, p.78).

A trama se passa num paupérrimo quarto de pensão, dividido por Tonho e Paco, companheiros de trabalho e de brigas corriqueiras. Tonho, ao realizar uma tarefa que normalmente era feita por outro, o negrão, provoca a fúria do mesmo, que passa a ameaçá-lo. Tonho, receoso mediante as ameaças, decidiu entregar parte do dinheiro do serviço e efetuar alguns pagamentos exigidos pelo negrão. A partir de então, Tonho é ridicularizado, considerado frágil e covarde, características essas que não condizem com uma personalidade máscula. Tonho a fim de evitar brigas, atura os desaforos do Negrão. O posicionamento de Tonho, dá margem à Paco apelidá-lo como "Boneca do Negrão". Tal apelido denota um sujeito afeminado, e ecoa para Paco como desonrado e indigno: 
TONHO - Como você pode dizer uma coisa dessas de mim?

PACO - Eu digo mesmo. Não ponho a mão no fogo por ninguém.

TONHO - Vida desgraçada! Tem que ser sempre assim. Cada um por si e se dane o resto. Ninguém ajuda ninguém. Se um sujeito está na merda, não encontra um camarada pra the dar uma colher de chá. E ainda aparecem uns 173miseráveis pra pisar na cabeça da gente. Depois, quando um cara desses se torna um sujeito estrepado, todo mundo acha ruim. Desgraça de vida!

PACO - Poxa, mas é assim mesmo. Que é que você queria? Que alguém fosse se virar por você? Se quiser isso, está louco. Vai acabar batendo a cuca no poste. Poxa, você acha que eu é que vou andar dizendo por aí que você não é bicha? Quero que você se dane! Se não é Boneca do Negrão, vai lá e limpa sua barra. (MARCOS, 2003, p.98-99)

\section{Plínio Marcos no alvo da censura}

A identidade dramatúrgica de Plínio fez com que suas peças enfrentassem dificuldades com a censura e muitas delas só foram encenadas com a queda do regime militar. Plínio destaca, que por conta da característica marginal em suas dramaturgias, foi alvo da censura antes mesmo de 1964:

Antigamente quando a censura era branda, isto é, antes de 1964 - eu digo branda porque eu tive peças proibidas antes de 1964 também - mas como a gente tinha mais margem de segurança, a gente sabia que se montasse uma peça e essa peça não desse certo, a gente podia montar outra. Hoje, a gente não sabe que pode montar ou não pode montar, porque às vezes a decisão é dada na última hora, na hora de abrir o palco (MARCOS apud COSTA, 2006, p. 226).

O dramaturgo salienta que há dois tipos de censura: "a policial, que nos impede de discutir até as últimas conseqüências o problema do homem; e a subvenção governamental, que é realmente constrangedora; e as companhias todas precisam dessa subvenção". (MARCOS apud KHÉDE, 1981, p.189)

Barrela foi a primeira peça de Plínio Marcos, escrita em 1958, e desde já demonstrava sua identidade dramatúrgica com feições contestadoras, sendo liberada somente na década de 1980. "Tive problemas com Barrela, quando começou, no governo do Juscelino - naquele tempo a censura era estadual e houve um tremendo 'pega pra capar'. A peça foi proibida" (MARCOS apud KHÉDE, 1981, p.202). O dramaturgo refere-se à censura regulamentada por lei, na qual o Estado intervém e proíbe a peça de ser encenada por fazer uso de temática sexual e uso exacerbado de palavrões. Magaldi destaca o posicionamento dos censores no que diz respeito à trama de Barrela:

[...] compete à censura federal a seleção de espetáculos públicos, visando a preservar a sociedade de influências lesivas ao consenso comum, tendentes a aviltar os padrões de valores morais e culturais coletivamente aceitos; os aspectos ofensivos ao decoro público inseridos em função de entretenimento popular tornam a representação antiestética e conseqüentemente comprometem-lhe o mérito artístico, há uma "profusão de seqüências obscenas, termos torpes, anomalias e morbidez explorados na peça [...], a qual é desprovida de mensagem construtiva, positiva, e de sansões e impulsos ilegítimos, o que torna inadequada a platéia de qualquer nível etário. (MAGALDI, 1998, p.207)

Plínio pontua que a censura estatal existe porque há censura moral. Os próprios membros da sociedade estabelecem coação moral de modo a marginalizar e 
reprimir indivíduos como mendigos, prostitutas e cafetões, personagens esses que constituem grande parte de sua dramaturgia. Plínio pontua que: "Nós vivemos numa sociedade hipócrita, onde todos falam contra a censura, mas onde todos exercem a censura a todo momento reprimindo o próximo" (MARCOS apud KHÉDE, 1981, p.186).

A peça Abajur Lilás, escrita pelo dramaturgo em 1969, foi impedida de ser levada aos palcos sob acusação de atentar contra a moral e bons costumes. A peça tem cinco personagens: três prostitutas (Dilma, Leninha e Célia), um homossexual cafetão (Giro) e seu capanga (Oswaldo), considerado um sadomasoquista assassino. A trama se passa num quarto de prostíbulo de última classe, com crescentes cenas de violência que se inicia de maneira irônica de modo a tomar dimensões avassaladoras. As prostituas são torturadas por Oswaldo a mando de Giro, sob acusação de uma delas ter quebrado o abajur lilás do cafetão.

Mecanismos de tortura, como o "pau- de- arara", presente tanto na época da ditadura quanto no texto de Plínio, evidencia a crítica do dramaturgo a tal período. Nota-se, então, uma similitude das práticas violentas presentes em Abajur Lilás com a tortura realizada na ditadura militar, para com aqueles que estavam inconformados com situação vigente e participavam direta ou indiretamente de agitações políticas.

Neste texto, após longa série de tortura, uma das prostitutas delata que foi Célia a responsável por quebrar o abajur lilás, o que acarreta a morte da acusada pelo capanga de Giro. Após presenciarem essa terrível cena, as outras duas prostitutas são obrigadas a continuarem o trabalho. Plínio evidencia o grupo marginalizado das prostituas, comumente abordado em suas peças. A profissão de prostituta, vista pela sociedade como trabalho fácil e regado de prazeres, é enfocada na dramaturgia pliniana a fim de estimular um repensar sobre a real condição de vida dessas mulheres. Em Abajur Lilás, o cafetão estabelece uma relação de subordinação para com as prostitutas, que necessitam do mesmo para trabalhar e Giro aproveita dessa circunstância para ditar as ordens. No primeiro ato da cena, o cafetão contrata Leninha para dividir o quarto com outras duas prostituas, a novata faz algumas cobranças em relação ao seu novo ambiente de trabalho, mas em seguida percebe o caráter autoritário de Giro:

Leninha - Hoje não vou pegar no batente. No primeiro dia, eu arrumo minhas coisas. E depois, vou sair pra comprar o abajur. Por isso, é bom tu trazer minha cama logo.

Giro - Quem tu pensa que é? Tu pensa que me dá ordens? Quem manda aqui sou eu. Sou o dono dessa merda. Gramei muito para ter isso aqui. E sou eu que mando. Trago a cama quando achar que devo. Pensa que eu vou pôr mulher aqui pra mandar? Eu sei o que faço. E se tu falar muito, não vai ter abajur nenhum.

Leninha - Tá, vai ser como tu quer. (MARCOS, 1969, p.37)

É notória a dependência das prostitutas, que se veem obrigadas a obedecer aos comandos de Giro, mas alimentam o desejo de serem autônomas, de modo a promover a ruptura da submissão que são mantidas. Por motivos particulares, as prostitutas continuam no trabalho. A personagem Dilma, por mais insatisfeita que esteja, é movida pela necessidade de criar seu filho pequeno e por essa circunstância não se imagina em outro emprego com remuneração suficiente para mantê-lo: 
DILMA - Sei de mim. Caí na putaria por quê? Porque estava na pior.

Ninguém entra nessa por gosto. Trepar é bom. Mas não é emprego. Enjoa. Aí, acaba o embalo. Fica tudo uma merda. Tanto faz a gente ir com um ou com outro. Sempre dá no mesmo. Só ando com macho por andar. Ninguém dá nada pra ninguém. Um sanduba de merda, uma cama que parece mais um chiqueiro do que cama, como a tua, ou outra porcaria qualquer, custa uma nota. Eu nunca tenho grana. Troco pelo que tenho, que é essa carne que a terra vai comer mesmo. [...]. (MARCOS: 1969, p.18)

Plínio Marcos recorreu, em 1975, no Supremo Tribunal Federal, à decisão do Ministro Falcão, que considerava a peça Abajur Lilás um atentado a moral e aos bons costumes, para assim conseguir a liberação de seu texto:

[...] porque ele dizia que a peça Abajur Lilás era um atentado contra a moral e os bons costumes, a gente exigia que explicasse por quê. Porque se uma peça fala contra a tortura, necessariamente ela não precisa ser a favor da tortura. A minha por exemplo, era contra a tortura. Se ela fala da exploração do homem pelo homem, era porque ela era contra a exploração do homem pelo homem. Se ela fala essas coisas todas, não quer dizer que eu seja a favor, muito pelo contrário, sou contra essas coisas. Mas ele dizia que eu atentava contra os bons costumes. (MARCOS apud KHÉDE, 1981, p.192)

Freire afirma que a peça é um "libelo", e não atenta contra a moral e os bons costumes. Ao contrário, pois ao tornar público a realidade das prostitutas e as imoralidades que são cometidas, torna-se notoriamente moral:

[...] nada indicam que se trata de uma obra imoral, ou propagadora dos maus costumes. Pelo contrário, trata-se de uma das mais terríveis e eloqüentes denúncias sobre o estado de um número razoável de homens e mulheres, que vivem o submundo marginal da prostituição e da exploração mais degradante do sexo. Quem assistisse tal peça- assim como quem a leu com o mínimo de espírito critico - sairia nauseado e horrorizado. O que prova que a peça nada tem de imoral, excitante ou propagadora da dissolução social. Nada do que ela exibe convida a repeti-la ou revivê-la. (FREIRE, 1977, p. 35)

O texto retrata as misérias sociais e humanas e o governo deveria enfrentar tal problema ao invés de censurá-lo. Por essa justificativa, Freire (1977) considera a atitude dos censores incoerente e primária, pois o efeito de incômodo que muitas vezes a peça acarreta, expõe a verdade do submundo marginalizado e cruel do país.

Verifica-se a originalidade dramatúrgica pliniana ao retratar o universo marginal em suas peças, como espécie de sociedade à parte, essa "anti-sociedade de tortos", como a chamou Hobsbawn (1976, p. 135), ou a sociedade de "dissidentes e dominados", à margem do processo pela desordem política (DA MATTA, 1983, p. 141).

Motivado pela busca da valorização da cultura popular, a fim de promover a discussão da realidade nacional, o desejo de Plínio, em relação à dramaturgia brasileira, incidia na liberdade aliada à responsabilidade do trabalho dos dramaturgos, para que as peças não fossem proibidas antes de serem levadas aos palcos:

O que a gente gostaria de ter nos nossos palcos é o seguinte: eu monto uma peça defendendo meu ponto de vista e sou responsável por ele e pela peça, que não deve passar por nenhuma censura prévia. Monto a peça. Depois então, se alguém achar que eu ofendo alguém ou alguma instituição, que abra um processo contra 
mim, e eu vou responder ao processo. Mas enquanto eu estiver respondendo ao processo, a peça não sai de cartaz, porque o fato de eu estar sendo processado não significa que eu seja culpado (MARCOS, 1976, p.52).

Plínio objetivava levar aos palcos a realidade das classes sociais do subproletariado urbano. A dramaturgia pliniana abre caminhos para protestos de grupos que se julgam oprimidos. Suas peças, alvo de censura no período ditatorial, são libelos à dura realidade dos marginalizados e atribuem ao social um pano de fundo que salienta os conflitos interindividuais, forçosamente psicológicos. Considerado autor marginal e maldito, sua forte característica dramatúrgica lança à sociedade o desafio a certa obrigação ética de tratar cruamente a realidade. 


\section{Referências}

ARISTÓTELES. A Política. São Paulo: Martins Fontes, 2001.

BAKHTIN, M. A cultura popular na Idade Média e no Renascimento. O contexto de François Rabelais. Tradução de Yara Frateschi Vieira. São Paulo: Hucitec, 2008.

BOAL, Augusto. Teatro do oprimido e outras poéticas políticas. Rio de Janeiro: Civilização Brasileira, 2008.

CACCIAGLIA, Mario. Pequena História do Teatro no Brasil. Trad. Carla de Queiroz. São: Paulo: USP, 1980.

CONTIERO, Lucinéia. Plínio Marcos: uma biografia. Tese de Doutorado em Letras, Assis (SP), UNESP, 2007.

COSTA, Cristina. Censura em cena: teatro e censura no Brasil. SP: EDUSP: FAPESP: Imprensa Oficial, 2006.

DA MATTA, R. Carnavais, malandros e heróis. Rio de Janeiro, Zahar, 1983.

FREIRE, Marcos. Nação Oprimida. Rio de Janeiro: Paz e Terra, 1977.

GASSNER, John. Mestres do teatro I. São Paulo: Perspectiva, 1974.

GERMANI, G. Consideraciones metodológicas e teoricas de la marginalidad. Santiago, Chile, 1970.

GOMES, Dias. O Engajamento: Uma prática de Liberdade. Civilização brasileira, Rio de Janeiro: Julho, ano IV - caderno especial no 2, p. 7 - 17, julho, 1968.

HOBSBAWN, H. Bandidos. Rio de Janeiro: Forense Universitária, 1976

KHÉDE, Sonia Salomão. Censores de Pincenê e Gravata: dois momentos da censura teatral no Brasil. Rio de Janeiro: Codecri, 1981.

MAGALDI, S. Moderna Dramaturgia Brasileira. São Paulo: Ed. Perspectiva, 1998.

MARCOS, Plínio. Quando as máquinas param. São Paulo: [s.n], 1967.

O abajur lilás; Oração para um pé-de-chinelo. São Paulo: Parma, 1969.

Uma história do cais do porto de Santos. Última Hora, 27/4/1969

Plínio Marcos. São Paulo: Global, 2003. 
MICHALSKI, Yan. O teatro sob pressão. Rio de Janeiro: Jorge Zahar, 1985

Reflexões sobre o teatro brasileiro no século XX. Rio de Janeiro: FUNARTE, 2005.

SANTOS, S. Ciclo de debates do Teatro Casa Grande. Rio de Janeiro: Ed. Inúbia, 1976. 